Introduction: In the era of the COVID-19 pandemic overlapping with the influenza season, the number of infections with the abovementioned viruses may result in overload in the healthcare system, difficulties in the diagnosis of respiratory diseases, poorer access to appropriate therapy, and increased mortality.

Aim of the study: The aim of this study was to analyze the influence of the COVID-19 pandemic on the decision to be vaccinated against seasonal influenza in cancer patients.

Material and methods: An anonymous survey prepared by the authors was made available to patients at the Chemotherapy Department at the Greater Poland Cancer Center. The survey covered 236 respondents, both female $(67.4 \%, n=159)$ and male $(32.6 \%$, $n=77$ ). A $0-10$ point numerical scale was used to assess the fear of coronavirus infection and the influenza. Data were collected from June 8 to September 30, 2020. The survey included 25 questions. The patients were informed by physicians about the voluntary and anonymous nature of the survey, to which they gave their ora consent. IBM SPSS Statistics 26 was used for the analysis.

Results: The vast majority of patients $(69.5 \%, n=164)$ have never been vaccinated against influenza and $30.5 \%(n=72)$ have been vaccinated at least once in the past. In the face of the COVID-19 pandemic, almost $1 / 4$ of the patients $(24.6 \%, n=58)$ stated that they wanted to be vaccinated against influenza. Only 33.5\% $(n=79)$ of the respondents believed that the influenza vaccine was effective.

Conclusions: Action is needed to increase the percentage of cancer patients who will be regularly vaccinated against the influenza. The COVID-19 pandemic may raise the interest of cancer patients in influenza vaccination.

Key words: cancer patients, COVID-19, influenza, vaccination.

Contemp Oncol (Pozn) 2021; 25 (3): 168-173 DOI: https://doi.org/10.5114/wo.2021.109417

\section{Seasonal influenza vaccination among cancer patients during the COVID-19 pandemic in Poland}

\author{
Mikolaj Bartoszkiewicz'1, Joanna Kufel-Grabowska²,3, Maria Litwiniuk ${ }^{4}$
}

${ }^{1}$ Department of Immunobiology, Poznan University of Medical Sciences, Poznań, Poland 2Department of Chemotherapy, University Hospital of Lord's Transfiguration,

Poznań, Poland

3Department of Electroradiology, Poznan University of Medical Sciences, Poznań, Poland ${ }^{4}$ Department of Cancer Pathology and Prevention, Poznan University of Medical Sciences, Poznań, Poland

\section{Introduction}

For years, Poland has had a record of a small proportion of the population enlisted in the seasonal influenza vaccination program. In the 2019/2020 season, only $4.12 \%$ of the Polish population was vaccinated against influenza, and 3.9\% in the previous season [1]. Vaccination remains the most effective public health method in mitigating and preventing seasonal influenza [2]. Influenza vaccination of the population reduces the risk of hospitalization of the elderly, risk of the need to treat adults in intensive care units, and reduces the risk of acute cardiac syndromes or exacerbation of chronic obstructive pulmonary disease in chronically ill people.

Patients with hematological malignancy and solid malignant tumors undergoing chemotherapy are exposed to potentially increased risk of influenzarelated complications [3]. Current scientific findings support the efforts to promote influenza vaccination in cancer patients and also recommend pneumococcal vaccination for immunocompromised patients, including patients with cancer $[4,5]$. In the era of the COVID-19 pandemic overlapping with influenza season, the number of infections with the abovementioned viruses may result in overload of the healthcare system, difficulties in the diagnosis of respiratory diseases, poorer access to appropriate therapy, and increased mortality.

This paper presents an analysis of vaccination plans against seasonal influenza during the COVID-19 pandemic among cancer patients in Poland.

\section{Aim of the study}

The aim of this study was to analyze the influence of the COVID-19 pandemic on the decision to be vaccinated against seasonal influenza in cancer patients.

\section{Material and methods}

An anonymous author's survey entitled "Influenza vaccination in the face of the COVID-19 pandemic among cancer patients" was made available to patients at the Chemotherapy Department at the Greater Poland Cancer Center. Data were collected from June 8 to September 30, 2020. The survey included 25 questions, 7 from the demographic part and 18 from the main part. The main portion of the survey was divided into four thematic parts, i.e., "Influenza vaccine in the past", "Patients' opinions about the vaccine", "Attitude of cancer patients to influenza vaccines" and "numerical scale". A 0-10 point numerical scale was used to assess the fear of coronavirus infection the influenza. The criterion for inclusion in the survey was the diagnosis of malignant cancer. Patients under cancer treatment or after treat- 
ment were allowed to participate in the study without being divided by kind of cancer treatment.

\section{Ethics}

The patients were informed by physicians about the voluntary and anonymous nature of the survey, to which they gave their oral consent. The anonymous author's survey does not require evaluation by the Bioethics Committee, which was confirmed by submitting the survey to the Bioethics Committee at the Karol Marcinkowski University of Medical Sciences in Poznań, 70 Bukowska Street, 60-812 Poznań.

\section{Statistics}

IBM SPSS Statistics 26 was used for the analysis. The significance level was assumed to be $<0.05$. The ShapiroWilk test was used to investigate whether the data have a normal distribution. To compare the percentages between the two groups, the Z-test was used. The chi-square test was used to compare the relations between data. The non-parametric Kruskal-Wallis test for independent variables was used to compare data distributions in different groups (due to the lack of normal distribution). The Bonferroni test was selected as a post-hoc test.

\section{Results}

\section{Respondents}

The survey covered 236 respondents, with a significantly greater percentage of women (67.4\%) than men (32.6\%). The average age for the whole group was 58.6, the median age was 61, for women the average age was 56.7 (median =59), and for men the average age was 62.6 (median =65).

More than $1 / 3$ of the respondents came from rural areas (36.9\%) and from cities with a population below 50,000 inhabitants (26.7\%) followed by cities with more than 250 thousand inhabitants $(22.0 \%)$. Almost half of the respondents were retired $(46.6 \%)$, more than $1 / 4$ were professionally active (27.1\%), and $19.1 \%$ of patients were receiving a pension.

Almost half of the respondents reported having secondary education (44.0\%), $1 / 4$ higher $(n=59)$ and $24.2 \%$ vocational. More than half of the patients participating in the study were diagnosed with breast cancer (53.8\%) followed by colorectal cancer (19.9\%); other cancers constituted less than $10 \%$ each: prostate cancer (7.6\%), liver cancer (3.8\%), gastric cancer (3. 8\%), pancreatic cancer (2.1\%), lung cancer $(1.7 \%)$, brain tumor (1.3\%), small intestine cancer, gall bladder cancer (each $n=2,0.8 \%$ ), carcinoma of the papilla of Vater, lymphoma, melanoma, liposarcoma, neuroma, bone cancer, head and neck cancer, esophageal cancer (each after $n=1,0.4 \%$ ). More than half of the patients (52.1\%) stated that so far, no distant metastases had been found.

\section{Main part of the survey}

Almost all patients (94.9\%) participating in the survey have heard of an influenza vaccine (Table 1, Q1). Nearly half of the respondents (48.3\%) knew for a long time that such a vaccine existed, while the remaining respondents most often found out from the media (28.8\%) (Table 1, Q2).
The vast majority of patients (69.5\%) have never been vaccinated against influenza and $30.5 \%$ have been vaccinated at least once in the past (Table 1, Q3-Q4).

Patients were asked to list the most common symptoms caused by the influenza virus; $81.4 \%$ indicated muscle pain (Table 2, Q1). In the surveyed group, 57 persons gave the correct answer, indicating the two most common symptoms, i.e. high fever and muscle aches. Only $33.5 \%$ of the respondents believed that the influenza vaccine was effective, half of them were unsure about its effectiveness (50.8\%) (Table 2, Q2), while only one in five respondents thought it was safe (19.9\%) (Table 2, Q3). Patients were asked whether the coronavirus is more infectious and whether it leads to death more often than the influenza virus. According to the vast majority of respondents (82.2\%), influenza vaccinations should be free (reimbursed to all citizens) (Table 2, Q4). More than 1/3 of the patients (36.9\%) could not tell the difference between these viruses (Table 2, Q5).

More than $1 / 3$ of the respondents were of the opinion that cancer patients should be vaccinated against influenza (34.3\%) (Table 3, Q1). Only 40.7\% of the patients believed that they could be vaccinated against influenza, but after consultation with their oncologist, and 28.0\% believed that influenza vaccination should be mandatory for patients during anticancer therapy (Table 3, Q2, Q5). According to $69.1 \%$ of the respondents, cancer patients are more likely to have severe post-influenza complications than people without cancer (Table 3, Q6).

In the face of the COVID-19 pandemic, almost $1 / 4$ of the patients $(24.6 \%)$ stated that they wanted to be vaccinated against influenza (Table 3, Q3). Those declaring willingness to be vaccinated expressed their conviction that the influenza vaccine could immunize them against the coronavirus (47.2\%) (Table 3, Q4).

The patients were asked about their fear of being infected with the SARS-CoV-2 and influenza viruses, as well as the fear of post-infection complications. The respondents expressed their opinions using a numerical scale, 0 - no fear, 10 - very strong fear. The average score related to SARS-CoV-2 infection in patients was 6.66 points (median $=7.00, \mathrm{SD}=2.67$ ) and to the influenza virus 5.49 points $($ median $=5.00, \mathrm{SD}=2.71$ ).

\section{Dependency study}

\section{Are women/men more afraid of influenza virus} infection than men/women are of SARS-COV-2?

The data in Table 4 are not normally distributed. To answer this question, the results obtained in the group of women and men for influenza and SARS-CoV-2 were compared with each other. Statistical analysis showed no significant difference between the fear of influenza virus $(p=0.880)$ and SARS-CoV-2 $(p=0.799)$ in women and men.

\section{Do women/men vaccinate more often than men/women? The analysis concerns previous vaccinations}

A comparison was made between the number of women $(32.1 \%)$ and men (27.3\%) who have vaccinated against influenza in the past. For this purpose, a Z-test was select- 
Table 1. Influenza vaccine in the past

\begin{tabular}{|c|c|c|c|c|}
\hline \multicolumn{5}{|c|}{ Q1. Have you heard of the flu vaccine? } \\
\hline & \multirow[t]{2}{*}{ Frequency $(n)$} & \multirow[t]{2}{*}{ Percent } & \multicolumn{2}{|c|}{ Z-test } \\
\hline & & & Statistic & $p$-value \\
\hline Yes & 224 & 94.9 & 19.516 & $<0.00001$ \\
\hline No & 12 & 5.1 & & \\
\hline \multicolumn{5}{|c|}{ Q2. If YES, how did you hear about the flu vaccine? } \\
\hline & Frequency $(n)$ & Percent & & \\
\hline From the attending physician & 11 & 4.7 & & \\
\hline From the media, i.e. television, the Internet & 68 & 28.8 & & \\
\hline From family, friends & 16 & 6.8 & & \\
\hline From the family doctor & 24 & 10.1 & & \\
\hline I have known for a long time that such a vaccine exists & 114 & 48.3 & & \\
\hline \multicolumn{5}{|c|}{ Q3. Have you ever had a flu vaccine in the past? } \\
\hline & \multirow[t]{2}{*}{ Frequency $(n)$} & \multirow[t]{2}{*}{ Percent } & \multicolumn{2}{|c|}{ Z-test } \\
\hline & & & Statistic & $p$-value \\
\hline Yes & 72 & 30.5 & & $<0.00001$ \\
\hline No & 164 & 69.5 & & \\
\hline \multicolumn{5}{|c|}{ Q4. Are you regularly (once a year) vaccinated against the flu? } \\
\hline & \multirow[t]{2}{*}{ Frequency $(n)$} & \multirow[t]{2}{*}{ Percent } & \multicolumn{2}{|c|}{ Z-test } \\
\hline & & & Statistic & $p$-value \\
\hline Yes & 26 & 11.0 & & $<0.00001$ \\
\hline No & 210 & 89.0 & & \\
\hline \multicolumn{5}{|c|}{ Q5. If you get the flu vaccine regularly, for how many years? } \\
\hline & Frequency $(n)$ & Percent & \multicolumn{2}{|c|}{$\begin{array}{l}\text { Percentage among people who } \\
\text { are vaccinated regularly }(n=39)\end{array}$} \\
\hline$<5$ years & 18 & 7.6 & 46.2 & \\
\hline $5-10$ years & 10 & 4.2 & 25.6 & \\
\hline$>10$ years & 11 & 4.7 & 28.2 & \\
\hline
\end{tabular}

ed: $z=0.751, p=0.4533$. There was no significant difference between the number of women and men who have vaccinated against influenza in the past.

\section{Discussion}

The European Union policy on influenza vaccination aims to protect people at higher risk of severe complications, either directly through vaccination or indirectly through vaccination of subgroups (e.g. healthcare workers or children) that may infect people at greater risk of severe infection, as highlighted in the 2009 EU Council Recommendation [6].

In our survey, the average age of patients was 58 years, only $30.5 \%$ of the respondents have been vaccinated against influenza in the past and only $11 \%$ have vaccinated regularly once a year, which reflects the data for Poland, where the average vaccination rate in the group $>65$ years old is about $10 \%$. The World Health Organization (WHO) recommends that at least $75 \%$ of people in the group $>65$ years of age should be vaccinated against influenza in the European region [7]. A survey conducted by Poeppl et. al. confirms that the participation of cancer patients in the influenza vaccination program is too low also in other
European countries. Only 80 out of 444 patients (18\%) were vaccinated against influenza in the previous year. The percentage of influenza vaccinations was higher among patients with hematological malignancy (22\%) compared to patients with solid malignant tumors (13\%) [8].

Cancer and cancer treatment have an immunosuppressive effect, leading to deterioration of the body's immunity. In addition, cachexia, lack of movement and tumor localization increase the risk of infection and worsen its course. The reduction of white blood cell count caused by chemotherapy or irradiation of the area where the bone marrow is produced causes the body to become defenseless and even a harmless infection can lead to the patient's death.

Vaccination in cancer patients should be carried out before the start of immunosuppressive therapy. It is recommended to use "live" vaccines at least four weeks before the expected immune deficiency and inactivated vaccines at least two weeks. Inactivated vaccines are not recommended, except for influenza and hepatitis B vaccination, which can be done between chemotherapy courses. Probably the best response to influenza vaccination can be obtained with this vaccine at least seven days after the last 
Table 2. Patients' opinions about the vaccine

\begin{tabular}{|c|c|c|}
\hline \multicolumn{3}{|c|}{$\begin{array}{l}\text { Q1. Do you know what the most common symptoms } \\
\text { of the flu virus are (multiple choice)? }\end{array}$} \\
\hline & Frequency $(n)$ & Percent \\
\hline High fever above $40^{\circ} \mathrm{C}$ & 166 & 70.3 \\
\hline Muscle ache & 192 & 81.4 \\
\hline Runny nose & 126 & 53.4 \\
\hline I don't know & 18 & 7.6 \\
\hline \multicolumn{3}{|c|}{ Q2. Do you think the flu vaccine is effective? } \\
\hline & Frequency $(n)$ & Percent \\
\hline Yes & 79 & 33.5 \\
\hline No & 37 & 15.7 \\
\hline I don't know & 120 & 50.8 \\
\hline \multicolumn{3}{|c|}{ Q3. Do you think the flu vaccine is safe for patients? } \\
\hline & Frequency $(n)$ & Percent \\
\hline Yes & 47 & 19.9 \\
\hline No & 20 & 8.5 \\
\hline I don't know & 169 & 71.6 \\
\hline \multicolumn{3}{|c|}{$\begin{array}{l}\text { Q4. Do you think flu vaccination should be free } \\
\text { (reimbursed for all citizens)? }\end{array}$} \\
\hline & Frequency $(n)$ & Percent \\
\hline Yes & 194 & 82.2 \\
\hline No & 11 & 4.7 \\
\hline I don’t know & 31 & 13.1 \\
\hline \multicolumn{3}{|c|}{$\begin{array}{l}\text { Q5. Do you know what the difference between } \\
\text { the flu and the coronavirus is? }\end{array}$} \\
\hline & Frequency $(n)$ & Percent \\
\hline It is easier to catch the coronavirus & 59 & 25.0 \\
\hline $\begin{array}{l}\text { The coronavirus is more likely to be } \\
\text { fatal than the flu virus }\end{array}$ & 78 & 33.1 \\
\hline These viruses are not different & 23 & 9.7 \\
\hline I don't know & 87 & 36.9 \\
\hline
\end{tabular}

chemotherapy course and at least two weeks before the next course [9].

Influenza vaccination is recommended for people with chronic diseases, including cancer, as well as the caregivers of cancer patients [10]. More than $40 \%$ of the patients participating in our survey thought that after consultation with an oncologist they could be vaccinated during anticancer treatment, while the vast majority of the respondents $(71.6 \%)$ did not know whether the vaccine was safe for cancer patients. About 1/3 of the respondents were of an opinion that the influenza vaccine should be obligatory for cancer patients. About $70 \%$ of the study participants believed that cancer patients were more likely to have severe influenza complications, as shown by scientific studies [11]. As a result, many guidelines recommend influenza vaccination for immunocompromised or immunosuppressed patients [12]. Active immunization in cancer patients has been shown to provide immunity with a similar frequency as in healthy individuals, resulting in a shorter duration and severity of infection and reduced morbidity and mortality [13].
Table 3. Attitude of cancer patients to flu vaccines

\begin{tabular}{|c|c|c|}
\hline \multicolumn{3}{|c|}{$\begin{array}{l}\text { Q1. Do you think cancer patients should get vaccinated against } \\
\text { influenza? }\end{array}$} \\
\hline & Frequency $(n)$ & Percent \\
\hline Yes & 81 & 34.3 \\
\hline No & 31 & 13.2 \\
\hline I don't know & 124 & 52.5 \\
\hline
\end{tabular}

Q2. In your opinion, can a cancer patient be vaccinated against flu during cancer therapy?

$\begin{array}{lcc} & \text { Frequency }(n) & \text { Percent } \\ \text { Yes, after consulting the oncologist } & 96 & 40.7 \\ \text { No } & 19 & 8.1 \\ \text { I don't know } & 121 & 51.2\end{array}$

\begin{tabular}{|c|c|c|}
\hline \multicolumn{3}{|c|}{$\begin{array}{l}\text { Q3. Will you be vaccinated against the flu in the face } \\
\text { of the prevailing COVID-19 pandemic? }\end{array}$} \\
\hline & Frequency ( $n$ ) & Percent \\
\hline Yes & 58 & 24.6 \\
\hline No & 70 & 29.7 \\
\hline I don't know & 108 & 45.7 \\
\hline
\end{tabular}

\begin{tabular}{|c|c|c|}
\hline \multicolumn{3}{|c|}{ Q4. If YES, why? (If NO, please skip this question) } \\
\hline & Frequency $(n)$ & Percent \\
\hline I'm afraid of the flu virus & 20 & 8.5 \\
\hline $\begin{array}{l}\text { The doctor recommended this } \\
\text { vaccination for me }\end{array}$ & 12 & 5.1 \\
\hline I get the flu vaccine regularly & 9 & 3.8 \\
\hline $\begin{array}{l}\text { I believe this vaccine may partially } \\
\text { immunize me against the coronavirus }\end{array}$ & 34 & 14.4 \\
\hline \multicolumn{3}{|c|}{$\begin{array}{l}\text { Q5. Do you think that flu vaccination should be mandatory } \\
\text { for cancer patients? }\end{array}$} \\
\hline & Frequency $(n)$ & Percent \\
\hline Yes & 66 & 28.0 \\
\hline No & 43 & 18.2 \\
\hline I don't know & 127 & 53.8 \\
\hline
\end{tabular}

Q6. Do you think that cancer patients are more likely to develop severe complications from influenza?

\begin{tabular}{lcc} 
& & \\
\cline { 2 - 3 } Yes & 163 & 69.1 \\
No & 10 & 4.2 \\
I don't know & 63 & 26.7
\end{tabular}

The low participation of cancer patients in the annual influenza vaccination program is undoubtedly related to their poor awareness of the safety and positive health effects of the vaccine. Only about $15 \%$ of patients have received information from their family doctor or oncologist about the possibility of vaccinationW, which should be common in the period preceding the influenza season. Recently, there have been movements of the so-called anti-vaccinationists, who associate vaccination with the occurrence of mental illness or autism. In the lack of specific information from the attending doctor or family doctor about the possibility of vaccination, it is difficult for patients to decide on their own. 
Table 4. Fear of SARS-CoV-2 and influenza virus infection in men and women

\begin{tabular}{|c|c|c|c|c|}
\hline & \multicolumn{2}{|c|}{ SARS-CoV-2 } & \multicolumn{2}{|c|}{ Influenza virus } \\
\hline & $\begin{array}{l}\text { Women } \\
(n=159)\end{array}$ & $\begin{array}{c}\text { Men } \\
(n=77)\end{array}$ & $\begin{array}{l}\text { Women } \\
(n=159)\end{array}$ & $\begin{array}{c}\text { Men } \\
(n=77)\end{array}$ \\
\hline Average & 6.65 & 6.68 & 5.50 & 5.47 \\
\hline Median & 7.00 & 7.00 & 5.00 & 5.00 \\
\hline Standard deviation & 2.639 & 2.750 & 2.723 & 2.688 \\
\hline Min & 0 & 1 & 0 & 0 \\
\hline Max & 10 & 10 & 10 & 10 \\
\hline Shapiro-Wilk test (normal distribution) & $\begin{array}{l}w=0.922 \\
p=0.000\end{array}$ & $\begin{array}{l}w=0.907 \\
p=0.000\end{array}$ & $\begin{array}{l}w=0.958 \\
p=0.000\end{array}$ & $\begin{array}{l}w=0.946 \\
p=0.003\end{array}$ \\
\hline
\end{tabular}

Table 5. Influenza vaccination in the past divided by gender

\begin{tabular}{|c|c|c|c|c|}
\hline & & \multicolumn{2}{|c|}{ Gender } & \multirow[t]{2}{*}{ Total } \\
\hline & & Women & Men & \\
\hline \multicolumn{5}{|c|}{$\begin{array}{l}\text { Have you ever been vaccinated } \\
\text { against influenza in the past? }\end{array}$} \\
\hline & \multirow[t]{2}{*}{ Yes } & 51 & 21 & 72 \\
\hline & & 32.1 & 27.3 & 30.5 \\
\hline & \multirow[t]{2}{*}{ No } & 108 & 56 & 164 \\
\hline & & 67.9 & 72.7 & 69.5 \\
\hline \multirow{2}{*}{\multicolumn{2}{|c|}{ Total }} & 159 & 77 & 236 \\
\hline & & 100.0 & 100.0 & 100.0 \\
\hline
\end{tabular}

Our analysis shows that more than $1 / 4$ of the respondents wanted to be vaccinated against influenza in the $2020 / 2021$ season, and about $45 \%$ have not yet made a decision. Almost half of the respondents (47.2\%) believed that influenza vaccination can protect against coronavirus infection; hence the likely increase in interest in influenza vaccination. There is no scientific evidence to support this hypothesis. From the recent analyses conducted by scientists, it can only be concluded that with the current strains of these two viruses, the clinical course of infection is not significantly worse than with the COVID-19 infection [14]. If $80 \%$ of the population had been vaccinated, even a vaccine effective only in $50 \%$ of people would still provide herd immunity [15], which would protect the oldest part of the population from complications.

The vast majority of respondents correctly identified the most common symptoms of influenza, i.e. high fever $>40^{\circ} \mathrm{C}(70.3 \%)$ and muscle aches (81.4\%). More than $1 / 3$ of the respondents claimed that the mortality rate was higher for the SARS-CoV-2 infection than for influenza virus infection, while about 10\% could not identify the differences between these viruses. According to the WHO, the mortality rate of SARS-CoV-2 is approximately $2-5 \%$ or $3.4 \%$ $[16,17]$, while that of the influenza virus is approximately $0.1-0.5 \%$. Patients are more afraid of the SARS-CoV-2 infection and the consequences of the COVID-19 disease than influenza virus infection.

Seasonal influenza for cancer patients is dangerous due to the risk of a severe course of disease and related complications, which is often associated with discontin- uation of cancer treatment. For the healthcare system, seasonal influenza is a recurring problem which causes an increase in the number of medical consultations and hospitalizations, thus putting an even greater burden on the healthcare system during the COVID-19 pandemic. The economic effects of influenza are felt in Europe every year. The total estimated direct and indirect costs of an influenza epidemic in high-income countries may reach EUR 56.7 million per million people. In Europe, influenza is the cause of about $10 \%$ of absence from work related to the disease, while the cost of lost productivity caused by influenza in France and Germany is estimated to be between EUR 6.4 billion and EUR 9.8 billion per year [18-20]. In Poland, the influenza vaccine is free for people over 75 years of age [21], while the patients participating in the survey were almost unanimous (82.2\%) that the influenza vaccine should be free for all Polish citizens. It is possible that the economic aspect would increase the participation of Polish society in the influenza vaccination program.

The intensive public debate on the current pandemic and appeals by physicians for an influenza vaccination in the 2020/2021 season have resulted in an increased interest in this vaccine, which in turn has contributed to the excess of demand over market opportunities and the lack of vaccine availability in the months preceding the period of the highest influenza incidence [22, 23].

Summarizing the results of the present survey, the following facts should be noted:

- only $11 \%$ of cancer patients have been regularly vaccinated against influenza,

- only $15 \%$ of patients have received information from their GP or oncologist about the possibility of vaccination,

- only $33.5 \%$ of patients believed that the influenza vaccine was effective,

- in the face of the prevailing COVID-19 pandemic, 24.6\% of patients declared their willingness to be vaccinated against influenza (Table 5).

\section{Conclusions}

Action is needed to increase the percentage of cancer patients who will be regularly vaccinated against influenza. The COVID-19 pandemic may increase the interest of cancer patients in influenza vaccination. 


\section{Acknowledgement}

One of the study limits is the numerical scale that was used to assess patients' fear. The authors chose a 0-10 numerical scale to assess the fear of coronavirus and influenza infection. The numerical scale has not been validated; it is only a subjective assessment of the patient. The authors wanted to show whether patients rated the fear of coronavirus infection or influenza higher.

\section{The authors declare no conflict of interest.}

\section{References}

1. Polish National Institute of Public Health. Available on: https:// szczepienia.pzh.gov.pl/faq/jaki-jest-poziom-zaszczepieniaprzeciw-grypie-w-polsce/

2. Nicoll A, Sprenger M. Low effectiveness undermines promotion of seasonal influenza vaccine. Lancet Infect Dis 2013; 13: 7-9

3. Boehmer LM, Waqar SN, Govindan R. Influenza vaccination in patients with cancer: an overview. Oncology (Williston Park) 2010; 24: $1167-1170$

4. Vinograd I, Eliakim-Raz N, Farbman L, et al. Clinical effectiveness of seasonal influenza vaccine among adult cancer patients. Cancer 2013; 119: 4028-4035.

5. Delacruz W, Terrazzino S, Osswald M, Payne C, Haney B. Implementing a multidisciplinary approach to enhance compliance with guideline-recommended prechemotherapy pneumococcal vaccination in a military-based medical oncology practice. I Oncol Pract 2017; 13: e966-e971.

6. Council Recommendation on seasonal influenza vaccination 2009. Available on: https://eurlex.europa.eu/legal-content/EN/ TXT/PDF/? uri=CELEX:32009H1019\&from=EN

7. WHO. Seasonal vaccination policies and coverage in the European Region. Available on: .https://www.euro.who.int/en/health-topics/communicable-diseases/influenza/vaccination/seasonal-vaccination-policies-and-coverage-in-the-european-region

8. Peoppl W, Lagler H, Raderer M, Sperr WR. Influenza vaccination perception and coverage among patients with malignant. Vaccine 2015; 33: 1682-1687.

9. Rubin LG, Levin MJ, Ljungman P, et al. 2013 IDSA clinical practice guideline for vaccination of the immunocompromised host. Clin Infect Dis 2014; 58: e44-e100.

10. Blanchette PS, Chung H, Pritchard KI, et al. Influenza vaccine effectiveness among patients with cancer: a population-based study using health administrative and laboratory testing data from Ontario, Canada. J Clin Oncol 2019; 37: 2795-2804.

11. Cooksley CD, Avritscher EB, Bekele BN, Rolston KV, Geraci JM, Elting LS. Epidemiology and outcomes of serious influenza-related infections in the cancer population. Clin Infect Dis 2020; 70: 193-199.

12. Kunisaki KM, Janoff EN. Influenza in immunosuppressed populations: a review of infection frequency, morbidity, mortality, and vaccine responses. Lancet Infect Dis 2009; 9: 493-504.

13. Ariza-Heredia EJ, Chemaly RF. Practical review of immunizations in adult patients with cancer. Hum Vaccin Immunother 2015; 11: 2606-2614.

14. Ding P, Lu Y, Fan Y, Xia M. The clinical characteristics of pneumonia patients coinfected with 2019 novel coronavirus and influenza virus in Wuhan, China. J Med Virol 2020; 92: 1549-1555.

15. Grech B, Borg M. Influenza vaccination in the COVID-19 era. Early Hum Dev 2020; 148: 105116.

16. WHO. Director general media briefing COVID-19 pandemic. Available on: https://www.who.int/dg/speeches/detail/who-directorgeneral-s-opening-remarks-at-the-media-briefing-on-covid-19--3-march-2020

17. Guo J-R, Cao Q-D, Hong Z-S, et al. The origin, transmission and clinical therapies on coronavirus disease 2019 (COVID-19) outbreak - an update on the status. Mil Med Res 2020; 7: 11.
18. European Centre for Disease Prevention and Control. Factsheet for health professionals. Available on: http://ecdc.europa.eu/en/ healthtopics/seasonal_influenza/basic_facts/Pages/factsheet_ professionals_seasonal_influenza.aspx

19. Ryan J, Zoellner Y, Gradl B, Palache B, Medema J. Establishing the health and economic impact of influenza vaccination within the European Union 25 countries. Vaccine 2006; 24: 6812-6822.

20. Keech M, Beardsworth P. The impact of influenza on working days lost: a review of the literature. Pharmacoeconom 2008; 26: 911-24.

21. Announcement of the Polish President of the Office of Medicinal Products of August 17, 2020 on human influenza vaccines for the 2020/2021 season. Available on: http://www.urpl.gov.pl/pl/komunikat-prezesa-urzędu-z-dnia-17-sierpnia-2020-r-w-sprawie-szczepionek-przeciw-grypie-stosowanych

22. Świdrak K. Hundreds of people in pharmacies ask for the influenza vaccine every day. When will it be available for purchase again? Available on: https://www.medonet.pl/zdrowie,w-aptekach-codziennie-setki-osob-pytaja-o-szczepionke-przeciw-grypie--kiedyznow-bedzie-mozna-ja-kupic-,artykul,36661834.html

23. Soroko A. Influenza vaccine in the pharmacy right away? Yes, but not in Poland. Available on: https://www.gdziepolek.pl/blog/szczepionka-na-grype-w-aptece-od-reki-tak-ale-nie-w-polsce

\section{Address for correspondence}

\section{Mikolaj Bartoszkiewicz}

Department of Immunobiology

Poznan University of Medical Sciences

8 Rokietnicka St.

60-806, Poznań, Poland

e-mail: m.bartoszkiewicz@ump.edu.pl

Submitted: 14.03 .2021

Accepted: 15.07 .2021 